\title{
Non-Vitamin K Antagonist Oral Anticoagulants in Atrial Fibrillation: Pharmacology and Phase III Clinical Trials
}

\author{
Keval K. Patel, Ali A. Mehdirad and Richard Lee \\ Additional information is available at the end of the chapter \\ http://dx.doi.org/10.5772/64440
}

\begin{abstract}
Atrial fibrillation $(\mathrm{AF})$ is a very common clinically significant arrhythmia noted in clinical practice. Its incidence increases with age and along with advanced age, other risk factors such hypertension, vascular disease, heart failure, diabetes, prior stroke and female sex determine the associated stroke risk with AF. For over 40 years warfarin has been the drug of choice used to reduce this stroke risk associated with AF. However, the narrow therapeutic range, dietary restrictions, and chronic monitoring with warfarin led to the development of novel oral anticoagulants (NOACs) such as dabigatran, rivaroxaban, apixaban, and edoxaban. The purpose of this chapter is to elucidate pharmacology and the clinical performance of these NOACs in the setting of non-valvular atrial fibrillation (NVAF).
\end{abstract}

Keywords: novel oral anticoagulants, non-valvular atrial fibrillation, dabigatran, rivaroxaban, apixaban, edoxaban, stroke prevention, atrial fibrilation

\section{Introduction}

Atrial fibrillation (AF) is one of the most common arrhythmias in clinical practice affecting approximately 2.3 million people in the United States and 4.5 million people in Europe. The incidence increases with age and the prevalence being $9 \%$ between the ages of 80 and 90 [1]. Other risk factors include hypertension, coronary artery disease, chronic obstructive pulmonary disease, valvular heart diseases or surgeries, hyperthyroidism and chronic alcoholism. The mortality rate in AF is twice that of age-matched individuals in normal sinus rhythm, and stroke risk is increased approximately fivefold in patients with non-valvular atrial fibrillation (NVAF) [2]. 
Over the last five decades, vitamin K antagonists (VKAs) such as warfarin have been the only oral anticoagulants available for use as a long-term treatment to prevent strokes in patients with AF. Aspirin (ASA) may be used for patients with NVAF who cannot take warfarin for one reason or another, but ASA is much less effective than warfarin and is therefore recommended only for NVAF patients at low risk of stroke (CHA2DS2-VASc score of 0 or 1 ) in the American College of Chest Physicians (ACCP) guidelines [2-4]. The CHA2DS2-VASc score is an improvement on the CHADS2 score which has been widely used in clinical practice to risk stratify patients with NVAF for stroke. The CHA2DS2-VASc added three risk factors, namely age 65-74, female sex, and history of vascular disease [5]. However, the clinical trials for novel oral anticoagulants (NOACs) were conducted prior to widespread implementation of the CHA2DS2-VASc score, and thus, the risk stratification used in the trials is CHADS2.

Several historical placebo-controlled trials in subjects with AF were conducted with warfarin between 1989 and 1999. A meta-analysis of these historical trials using a fixed effects model showed that the relative risk reduction of stroke by warfarin was $62 \%(95 \%$ CI: $0.48,0.72)$ with an absolute risk reduction of $2.7 \%$ for primary prevention and $8.4 \%$ for secondary prevention per year [2].

Although warfarin has been proven to be highly effective in preventing strokes, there have been multiple issues such as periodic monitoring, dietary restrictions, medication restrictions or interactions, and concerns for bleeding which render many patients with NVAF ineligible to receive warfarin therapy. For example, a registry of patients discharged from hospital revealed that only $54 \%$ of eligible AF patients received warfarin [6]. Likewise, surveys have indicated that many patients with AF cannot or will not take warfarin. Only $10 \%$ of patients with known AF who presented with an acute ischemic stroke had a therapeutic INR on admission, and even in those AF patients with a prior history of stroke or transient ischemic attack (TIA), only $18 \%$ had a therapeutic INR on admission [7]. Furthermore, studies show that the risk of intracranial hemorrhage was more than twice that of patients taking aspirin [2]. Thus, there was a need to develop an anticoagulant that would have similar or better efficacy as compared with warfarin along with better safety and more convenient management. Dabigatran, rivaroxaban, apixaban, and edoxaban have been approved over the past five years to satisfy this need.

\section{Pharmacology}

\subsection{Mechanism of action}

Dabigatran acts as a competitive reversible direct inhibitor of thrombin thereby preventing the thrombin-dependent conversion of fibrinogen to fibrin in the coagulation cascade. Rivaroxaban, apixaban, and edoxaban are direct competitive inhibitors of factor Xa, thereby inhibiting the formation of thrombin from prothrombin and downstream formation of fibrin from 
fibrinogen. And since factor Xa is located at the top of the final common coagulation pathway, rivaroxaban, apixaban, and edoxaban can affect both the intrinsic and extrinsic coagulation cascades. These target coagulation factors and other pharmacological parameters for each drug are summarized in Table 1.

\begin{tabular}{|c|c|c|c|c|}
\hline Characteristic & Dabigatran & Rivaroxaban & Apixaban & Edoxaban \\
\hline Target & Factor IIa & Factor Xa & Factor Xa & Factor Xa \\
\hline Molecular weight (Dal) & 724 & 436 & 460 & 738 \\
\hline $\mathrm{Ki}(\mathrm{nmol} / \mathrm{l})$ & 4.6 & 0.4 & 0.08 & 0.56 \\
\hline $\begin{array}{l}\text { Concentration to double PT } \\
(\mu \mathrm{mol} / \mathrm{l})\end{array}$ & 0.8 & 0.23 & 0.08 & 0.26 \\
\hline $\begin{array}{l}\text { Concentration to double PTT } \\
(\mu \mathrm{mol} / \mathrm{l})\end{array}$ & 0.23 & 0.69 & 7.4 & 0.51 \\
\hline Reversible binding & Yes & Yes & Yes & Yes \\
\hline Reversal of antithrombotic effect & $\begin{array}{l}\text { Specific antidote: } \\
\text { Idarucizumab } \\
\text { May consider PCC, } \\
\text { APCC, rFVIIa }\end{array}$ & $\begin{array}{l}\text { May consider PCC, } \\
\text { APCC, rFVIIa }\end{array}$ & $\begin{array}{l}\text { May consider } \\
\text { PCC, APCC, } \\
\text { rFVIIa }\end{array}$ & $\begin{array}{l}\text { May consider PCC, } \\
\text { APCC, rFVIIa }\end{array}$ \\
\hline Half-life (h) & $12-17$ & $5-9$ & 12 & $10-14$ \\
\hline Cmax (h) & 1 & $2-4$ & $3-4$ & $1-2$ \\
\hline Volume of distribution (1) & $50-70$ & $\sim 50$ & 21 & 107 \\
\hline Protein binding & $35 \%$ & $92-95 \%$ & $87 \%$ & $55 \%$ \\
\hline Renal excretion & $80 \%$ & $66 \%$ & $27 \%$ & $50 \%$ \\
\hline Accumulation & None & None & None & None \\
\hline Age effect & None & None & $\mathrm{Yes}^{\S}$ & None \\
\hline Sex effect & None & None & None & None \\
\hline Body weight effect & None & None & Yes & Yes \\
\hline Effect of food & Yes $^{*}$ & Yes & None & None \\
\hline $\begin{array}{l}\text { Primary hepatic clearance } \\
\text { pathway }\end{array}$ & No & CYP3A4 & CYP3A4 & No \\
\hline Pregnancy category & $\mathrm{C}$ & $\mathrm{C}$ & B & $\mathrm{C}$ \\
\hline
\end{tabular}

* Increases Cmax to $2 \mathrm{~h}$ but does not affect bioavailability.

$\S$ Dosage reduction recommended if two of the following three risk factors present: body weight $<60 \mathrm{~kg}$, age $>80$ years or serum creatinine $>1.5 \mathrm{mg} / \mathrm{dl}$.

Table 1. Pharmacokinetics and pharmacodynamics.

\subsection{Absorption}

Dabigatran itself is not absorbed via the oral route; however, its prodrug dabigatran etexilate is rapidly absorbed (bioavailability $3-7 \%$ ) via the oral route and is converted to the active 
ingredient by esterase-mediated hydrolysis in the liver. The absorption increases significantly when the capsules are broken, and thus, the capsules should not be broken or chewed or opened prior to administration. Additionally, when taken concomitantly with highly fatty food, the time to maximal concentration ( $\mathrm{Cmax}$ ) increases from 1 to $2 \mathrm{~h}$ but the bioavailability is not affected [8]. Rivaroxaban is rapidly absorbed in the proximal intestine with maximum concentrations (Cmax) appearing $2-4 \mathrm{~h}$ after tablet intake with the absolute bioavailability of $80 \%$ for the $10 \mathrm{mg}$ dose and $66 \%$ for the $20 \mathrm{mg}$ dose. The bioavailability is decreased when the drug is absorbed in the distal intestine or ascending colon [9]. This is an important consideration for patients with gastric bypass or other GI conditions that cause rapid transit. When taken with food, both the Cmax and the bioavailability of rivaroxaban (for both 15 and $20 \mathrm{mg}$ doses) increases by 39 and $76 \%$, respectively [9]. Thus, it is recommended that rivaroxaban be taken with a large meal (ideally dinner) and not a light meal in order to slow down the transit time.

Unlike the first two, apixaban is absorbed throughout the gastrointestinal tract, and therefore, the drug displays a prolonged absorption which is not affected by food intake. The absolute bioavailability of apixaban is $50 \%$ for doses up to $10 \mathrm{mg}$ with a Cmax of $3-4 \mathrm{~h}$. The distal small bowel and ascending colon account for $55 \%$ of the absorption of apixaban. Thereby, making it a better choice for patients with gastric bypass or other gastrointestinal conditions which lead to rapid transit, whereas in patients with colectomies or Crohn's disease, etc., apixaban's absorption may be altered and the drug may not be as readily available.

Edoxaban is also absorbed predominantly by the upper gastrointestinal tract with Cmax of 1$2 \mathrm{~h}$ and bioavailability of $62 \%$. The colon only accounts for $12 \%$ of absorption, thereby rendering the absorption of the drug susceptible to conditions that cause rapid transit, similar to rivaroxaban [10]. However unlike rivaroxaban, the absorption of edoxaban is not significantly affected by food intake.

\subsection{P-glycoprotein transporter, cytochrome P-450 (CYP) enzymes, and drug interactions}

The pro-drug dabigatran etexilate is a substrate for the efflux transporter P-glycoprotein ( $\mathrm{p}$ GP) transporter. And even though it neither induces nor inhibits $\mathrm{p}-\mathrm{GP}$, potential co-administration of other drugs that inhibit or induce P-GP can affect its bioavailability. The pharmacokinetics of dabigatran were not altered by another p-GP substrate digoxin, but an inhibitor like pantoprazole decreased the bioavailability by $30 \%$ [11]. Since H2 blocker ranitidine has no effect on the p-GP transporter, there was no effect on the area under the curve (AUC) when dabigatran was co-administered. For other p-GP inhibitors such as dronedarone or systemic ketoconazole, dosage adjustment was required in patients with reduced creatinine clearance (30-50 $\mathrm{ml} / \mathrm{min}$ ) [8]. Other $\mathrm{p}$-GP inhibitors such as amiodarone and verapamil only modestly increased plasma concentrations ( 13 and $20 \%$, respectively), and dose adjustment is not required for these medications [11]. On the other hand, potent p-GP inducers such as such as rifampin significantly reduced the AUC and Cmax of dabigatran and concomitant use should therefore be avoided. Dabigatran is neither a substrate, nor an inducer or inhibitor of CYP enzymes [8]. 
Rivaroxaban is a substrate for p-GP transporter, CYP3A4/5 enzymes, and other transporters such as ATP-binding cassette G2 [9]. Approximately 51\% of orally administered rivaroxaban is metabolized by the CYP enzymes 3A4 and 3A5. Thus, inhibition or induction of these proteins can lead to changes in the bioavailability of the drug. When studied with rifampin or phenytoin (p-GP and strong CYP3A4 inducers), the exposure to rivaroxaban decreased by $50 \%$. Similarly, other combined strong p-GP, CYP3A4 inducers such as carbamazepine, phenytoin, rifampin, and St. John's wort should be avoided in patients taking rivaroxaban. For drugs that are combined p-GP and CYP3A4 inhibitors (ketoconazole, ritonavir, clarithromycin, and erythromycin) or a moderate CYP3A4 inhibitor (fluconazole), studies showed increases in rivaroxaban exposure [9]. A dosage adjustment to $15 \mathrm{mg}$ is required when taking these medications concomitantly in patients with decreased creatinine clearance $(\mathrm{CrCl} 15-50 \mathrm{ml} /$ min). Additionally, rivaroxaban also has a low inhibitory effect on the p-GP transporter. Regardless, there were no significant interactions with $7.5 \mathrm{mg}$ single dose of midazolam (substrate of CYP3A4), $0.375 \mathrm{mg}$ once-daily dose of digoxin (substrate of p-GP), and $20 \mathrm{mg}$ once-daily dose of atorvastatin (substrate of CYP3A4 and p-GP) in healthy volunteers [12]. This is interesting because although neither dabigatran nor rivaroxaban has significant interactions with digoxin, rivaroxaban may be a better choice for patients with severe ischemic cardiomyopathy and NVAF because of an increased incidence of myocardial infarctions seen with dabigatran (discussed later).

Like dabigatran, apixaban is also a substrate for p-GP efflux transporter but unlike dabigatran, inhibition of p-GP transporter by itself does not affect the bioavailability. The drug is also metabolized by CYP3A4 and co-administration with drugs that are strong inducers and inhibitors for both p-GP and CYP3A4 increases the exposure to apixaban and raises the risk of bleeding. Rifampin, carbamazepine, phenytoin, and St. John's wort are strong combined inducers of p-GP and CYP34A and thus concomitant use should be avoided due to reduced exposure to apixaban. Ketoconazole, itraconazole, ritonavir, clarithromycin are strong dual inhibitors of p-GP and CYP3A4 and thus can increase exposure to apixaban [13]. Dose adjustment to $2.5 \mathrm{mg}$ is recommended when apixaban is taken concomitantly with these medications. If the patient is already on the reduced dose $(2.5 \mathrm{mg})$ of apixaban for other reasons, concomitant use of these medications is contraindicated [13]. Apixaban does not inhibit or induce p-GP and its potential to inhibit or induce CYP enzymes is minimal and as such the ability of apixaban to alter the exposure of co-administered drugs that are metabolites for these enzymes is minimal.

Unlike rivaroxaban and apixaban, CYP enzymes only account for $4 \%$ of the exposure to edoxaban. However, the intestinal p-GP transporter plays a significant role in clearance of the drug and thus inhibition of the transporter leads to increased exposure. Clinical interaction studies showed exposure to edoxaban increased by $87,77,53,85,73,40$, and $85 \%$ when used concomitantly with ketoconazole, quinidine, verapamil, erythromycin, cyclosporine, amiodarone, and dronedarone, respectively [10]. Subsequently in ENGAGE trial, the edoxaban was halved to $30 \mathrm{mg}$ in patients who were taking verapamil, quinidine, or dronedarone [14]. And in the HOKUSAI VTE study, the dose was reduced for patients taking verapamil, quinidine, azithromycin, clarithromycin, erythromycin, itraconazole, or ketoconazole [15]. The use of 
edoxaban should be avoided when taking a potent p-GP inducer like rifampin, phenytoin, carbamazepine, and St. John's wort [16].

\subsection{Elimination}

In the phases II and III of the RE-LY trial, dabigatran was administered in oral, intramuscular, and intravenous formulations. After oral administration of radiolabeled dabigatran, 82.6$88.6 \%$ of radioactivity was recovered in the feces and $7 \%$ was recovered in the urine, the remaining was attributed to incomplete absorption of dabigatran. Renal clearance of intravenous dabigatran was approximately $80 \%$. After infusion, the total clearance of dabigatran was found to be $92-141 \mathrm{ml} / \mathrm{min}$, and the renal clearance was $81-106 \mathrm{ml} / \mathrm{min}$ showing that dabigatran is almost exclusively excreted via glomerular filtration and there was no secretion or reabsorption further down the tubule $[7,13]$. The terminal half-life was $12-17 \mathrm{~h}$ in healthy individuals. The half-life was confounded by renal impairment and was increased to 15,18 , and $27.2 \mathrm{~h}$, respectively, in mild (50-80 $\mathrm{ml} / \mathrm{min})$, moderate (30-50 $\mathrm{ml} / \mathrm{min})$, and severe (15-30) renal insufficiency. The total exposure (or AUC) also increased by approximately 1.5-, 3.2-, and 6.3-fold in mild, moderate, and severe renal impairment, respectively, when compared to normal renal function. It is thus recommended that the dose of dabigatran for atrial fibrillation be halved to $75 \mathrm{mg}$ when the creatinine clearance $(\mathrm{CrCl})$ is between 15 and $30 \mathrm{ml} / \mathrm{min}$ for and the use of dabigatran should be avoided in patients with $\mathrm{CrCl}$ less than $15 \mathrm{ml} / \mathrm{min}$ or those on dialysis [8]. Administration of dabigatran in patients with moderate (Child-Pugh class B) liver impairment showed large inter-subject variability, but no evidence of a consistent change in exposure or pharmacodynamics because the primary elimination pathway for dabigatran is via the kidneys [8].

Off the orally administered radiolabeled rivaroxaban, $66 \%$ was recovered in the urine $36 \%$ unchanged) and $28 \%$ was recovered in the feces $(7 \%)$. The renal excretion of rivaroxaban is primarily driven by active tubular secretion and secondarily by glomerular filtration in a 5:1 ratio. The terminal half-life is $5-9 \mathrm{~h}$ in healthy young individuals $[9,12]$. Like dabigatran, the exposure to rivaroxaban also increases by $44 \%$ for mild, $52 \%$ for moderate, and $66 \%$ for severe renal impairment. As such, it is recommended that the dose of rivaroxaban for stroke prevention in NVAF be reduced to $15 \mathrm{mg}$ orally with dinner in patients with moderate-to-severe renal impairment $(\mathrm{CrCl} 15-50 \mathrm{ml} / \mathrm{min})$ due to increased exposure and rivaroxaban should be avoided in patients with $\mathrm{CrCl}<15 \mathrm{ml} / \mathrm{min}$ or those on dialysis. Rivaroxaban was not studied in patients with severe (Child-Pugh class $\mathrm{C}$ ) hepatic impairment, and exposure to rivaroxaban increased by 15 and $127 \%$ in patients with Child-Pugh class A and B hepatic impairment [9].

Unlike dabigatran and rivaroxaban, apixaban is excreted in both urine and feces. Renal excretion accounts for $27 \%$ of total clearance and biliary, and direct intestinal excretion accounts towards the fecal elimination of apixaban. The terminal half-life is $12 \mathrm{~h}$, and the exposure is not significantly affected $(<1.5 \times$ normal $)$ for any level of renal impairment including end-stage renal disease. Thus, no dosing adjustment is recommended kidney disease alone. However, a dosage reduction of apixaban to $2.5 \mathrm{mg}$ is recommended in patients that meet another one of the following two risk factors: age $>80$ years or body weight $<60 \mathrm{~kg}$ [13]. However, it should be noted that patients with end-stage renal disease $(\mathrm{CrCl}<15 \mathrm{ml} / \mathrm{min})$ were 
not studied in the clinical efficacy and safety trials [16]. The recommendation for no dosage adjustment is based on pharmacokinetic data showing a modest $17 \%$ increase in apixaban exposure in patients receiving hemodialysis with an elimination via dialysis of $18 \mathrm{ml} / \mathrm{min}$ reducing exposure of the drug by $14 \%$ postdialysis as compared to off dialysis period. Similarly, in patients with mild (Child-Pugh A) and moderate (Child-Pugh B) hepatic impairment, the area under the curve or exposure did not change significantly as compared to normal individuals and no dose adjustment is necessary in patients with Child-Pugh class A hepatic impairment. However, since patients who have Child-Pugh class B hepatic impairment may have intrinsic coagulation abnormalities, a recommendation on dosing cannot be made due to limited clinical experience. Like the others, use of apixaban is not recommended in patients with severe (Child-Pugh class C) hepatic impairment [13].

Edoxaban is excreted as unchanged drug in the urine with renal clearance accounting for $50 \%$ of total clearance. Metabolism as well as biliary and intestinal excretion accounts for the remaining clearance. The terminal half-life is $10-14 \mathrm{~h}$. In a pharmacokinetic study, the total systemic exposure to edoxaban increased by 32,74 , and $72 \%$ in patients with mild (50-80 ml/ $\mathrm{min})$, moderate $(30-50 \mathrm{ml} / \mathrm{min})$, severe $(15-30 \mathrm{ml} / \mathrm{min})$ renal impairment, and by $93 \%$ in patients receiving dialysis. Thus, a reduction in dose to $30 \mathrm{mg}$ daily is recommended in patients with $\mathrm{CrCl} 15-50 \mathrm{ml} / \mathrm{min}$ for stroke prevention in non-valvular atrial fibrillation $[10,16]$. Interestingly, the incidence of stroke was higher in patients receiving edoxaban who had a $\mathrm{CrCl}>95 \mathrm{ml} / \mathrm{min}$ as compared to warfarin in the clinical trial and the use of edoxaban is not recommended in these patients [10,14]. There were no significant differences for edoxaban in patients with mild or moderate (Child-Pugh class A or B) hepatic impairment. A dose adjustment is not necessary for Class A patients; however, once again due to the intrinsic coagulation abnormalities in patients with class B hepatic impairment, the use of edoxaban is not recommended [16].

\subsection{Special populations}

The pharmacokinetics and pharmacodynamics of both dabigatran and rivaroxaban are not affected by age, gender, or body weight. There is no effect of ethnicity on the pharmacology of dabigatran either, but rivaroxaban did have $20-40 \%$ higher exposure in patients of Japanese ethnicity as compared to other ethnicities including Chinese [9]. This exposure was reduced when it was corrected for body weight, but further studies may be required to assess clinical implications to the use of rivaroxaban in the Japanese population specifically. Although individually aged over 80 years and body weight $<60 \mathrm{~kg}$ only modestly increased the exposure to apixaban $(<1.5 \times$ normal individuals), the combination of the two risk factors was deemed to have a significant increase in the exposure of the drug. Thus, a reduced dose of $2.5 \mathrm{mg}$ was used in ARISTOTLE for patients who had two of the following three risk factors: age older than 80 years, body weight $<60 \mathrm{~kg}$, and creatinine $>1.5 \mathrm{mg} / \mathrm{dl}[13,17]$. Age is not a risk factor for increased exposure of edoxaban but a phase II open-label study done in Japan revealed that patients with total body weight $<60 \mathrm{~kg}$ had double the bleeding risk as compared to patients with total body weight $>60 \mathrm{~kg}$. Thus, in the phase III clinical trial, the dose of edoxaban was reduced to $30 \mathrm{mg}$ daily in patients with total body weight $<60 \mathrm{~kg}[14,16]$. 
Dabigatran, rivaroxaban, and edoxaban are all under category $\mathrm{C}$ for pregnancy. Animal studies showed increased maternal bleeding and increased fetal mortality with all three drugs. There was decreased fetal implantation with dabigatran, and increased post-implantation loss, and decreased fetal weight with rivaroxaban and edoxaban $[8,9,16]$. Additionally, there was decrease in gall bladder size or absence of the organ with the use of edoxaban in animal studies. Ten pregnancies were reported during the HOKUSAI VTE study, from which there were four full-term births, two preterm births, one spontaneous abortion in the first trimester, and three elective terminations during the study $[15,16]$. In comparison, animal studies with apixaban did not cause an increase in fetal toxicity, malformations, or mortality. There was an increase in the rate of maternal bleeding at the rate of 19, 4, and 1 times, respectively, for mice, rats, and rabbits with apixaban. As a result, the use of apixaban is under category B for pregnancy [13]. None of the NOACs are recommended for mothers who are breastfeeding, and the use of these drugs has not been studied in the pediatric population.

\section{Clinical trials}

\subsection{Trial designs}

The Randomized Evaluation of Long-term Anticoagulation Therapy (RE-LY) trial was designed as a non-inferiority trial to compare dabigatran to warfarin in 18, 113 patients from 951 clinical centers in 44 countries. Two doses of dabigatran; 110 and $150 \mathrm{mg}$ were administered in a double-blinded fashion [18]. We will discuss the data for the $150 \mathrm{mg}$ dose of dabigatran as FDA approval was only obtained for 150 and $75 \mathrm{mg}$ (not studied) doses. The warfarin arm was not blinded because the patients taking it needed regular follow-ups for INR control. The semi-blinded design of RE-LY could leave the trial open to reporter bias. Thus, the authors of the trial tried to minimize this bias by assigning two independent investigators who were unaware of the treatment assignments, to adjudicate each event. In addition, all hospital records were reviewed to ensure that all events were detected and correctly documented [18]. In contrast, the other three trials were designed in a double-blinded double dummy randomized fashion to avoid reporter bias.

The Rivaroxaban Once-Daily Oral Direct Factor Xa Inhibition Compared with Vitamin K Antagonism for Prevention of Stroke and Embolism Trial in Atrial Fibrillation (ROCKET-AF) trial studied Warfarin in comparison with $20 \mathrm{mg}$ of rivaroxaban in 14,264 patients from 1178 centers in 45 countries [19]. Similarly, the apixaban for Reduction in Stroke and Other Thromboembolic Events in Atrial Fibrillation (ARISTOTLE) study enrolled 18,201 patients at 1034 sites in 39 countries and Effective Anticoagulation with Factor Xa Next Generation in Atrial Fibrillation-Thrombolysis in Myocardial Infarction 48 (ENGAGE AF-TIMI 48) enrolled 21,105 patients from 1393 centers in 46 countries to study apixaban $5 \mathrm{mg}$ and edoxaban $60 \mathrm{mg}$ to warfarin, respectively [14, 17].

Lower doses of NOACs were studied in ROCKET, ARISTOTLE, and ENGAGE. Rivaroxaban $15 \mathrm{mg}$ was used for patients with creatinine clearance $15-50 \mathrm{ml} / \mathrm{min}$ [19]. For ARISTOTLE, 
apixaban dose was reduced to $2.5 \mathrm{mg}$ twice daily if the patient had two of the following three risk factors for increased bleeding: age $\geq 80$ years, body weight $\leq 60 \mathrm{~kg}$, or a serum creatinine level $\geq 1.5 \mathrm{mg}$ per deciliter [17]. In ENGAGE, randomization was done in 1:1:1 fashion for warfarin, edoxaban $60 \mathrm{mg}$, and edoxaban $30 \mathrm{mg}$. The doses of edoxaban were further halved to 30 and $15 \mathrm{mg}$ for patients who either had a creatinine clearance $30-50 \mathrm{ml} / \mathrm{min}$ or body weight $\leq 60 \mathrm{~kg}$ thereby allowing a range of doses from 15 to $60 \mathrm{mg}$ to be used in the study [14]. However, the results of the study were more promising from the $60 \mathrm{mg}$ dose with reduction to $30 \mathrm{mg}$ for specific patients leading to FDA approval. Thus, for the scope of this chapter, only the results pertaining edoxaban $60 \mathrm{mg}$ daily dose will be discussed.

Additionally, ROCKET-AF used both intention-to-treat and on-treatment analyses, and the outcomes listed as number of events per 100 patient-years (instead of percent per year) [19]. To facilitate comparisons between trials, only the intention-to-treat analyses are reported in this chapter. Similarly, ENGAGE also had a prespecified intention-to-treat analysis to assess superiority to warfarin which was not statistically significant and thus will not be discussed for the purposes of this chapter.

\subsection{Patient populations}

All four trials used similar criteria for enrolling and following patients with subtle differences as listed in Table 2. However, these subtle differences may affect decision-making in different clinical scenarios. For example, only ENGAGE included patients with prior bioprosthetic valve or valve repair and as such edoxaban may be the preferred agent for stroke prevention in these patients. Similarly, for newly diagnosed strokes, ARISTOTLE excluded patients with strokes within 7 days of randomization. RE-LY, ROCKET, and ENGAGE excluded patients with strokes within 6, 3, and 1 month, respectively. RE-LY and ROCKET also excluded patients with transient ischemic attack (TIA) within 14 days and thus if a patient has had a stroke more than 7 days prior to and within 1 month of planned anticoagulation, apixaban may be the preferred agent. ARISTOTLE also included patients with creatinine clearance less than $30 \mathrm{ml} / \mathrm{min}$ and had the most patients in this category. As such in the absence of other risk factors for bleeding and increased exposure to apixaban, the use of apixaban would be preferred in these patients.

Another important consideration is the CHADS2 score used in the trial, because higher scores are associated with incrementally higher risk of stroke. Both ROCKET and ENGAGE required a minimum $\mathrm{CHADS}_{2}$ score of 2 to be included in the trial. Additionally, ROCKET also permitted patients with lower left ventricular ejection fractions, thus enrolling a higher risk patient population than RE-LY and ARISTOTLE. Roughly one-third of patients in RE-LY and ARISTOTLE had $\mathrm{CHADS}_{2}$ scores of 0 or 1, resulting in an overall 1\% lower absolute risk of stroke in those patients as compared to those enrolled in ROCKET or ENGAGE. Even though the $\mathrm{CHADS}_{2}$ score was evenly distributed between the drug and warfarin groups were evenly distributed in both trials, the overall incidence of primary outcome could be overestimated for the ROCKET and ENGAGE trials. 


\begin{tabular}{|c|c|c|c|c|}
\hline Characteristic & RE-LY & ROCKET & ARISTOTLE & ENGAGE \\
\hline Drug & Dabigatran & Rivaroxaban & Apixaban & Edoxaban \\
\hline Dosing & $150 \mathrm{mg}$ BID (75 mg) & $20 \mathrm{mg}$ daily (15 mg) & \multicolumn{2}{|c|}{$\begin{array}{c}5 \mathrm{mg} \text { BID (2.5 mg) } 60 \mathrm{mg} \text { daily (30 } \\
\mathrm{mg})\end{array}$} \\
\hline $\begin{array}{l}\text { Total population } \\
(\mathrm{N})\end{array}$ & 18,113 & 14,266 & 18,206 & 21,105 \\
\hline Design & PROBE & Double blinded & Double blinded & Double blinded \\
\hline $\begin{array}{l}\text { Primary efficacy } \\
\text { endpoint }\end{array}$ & $\begin{array}{l}\text { Stroke or systemic } \\
\text { embolism }\end{array}$ & $\begin{array}{l}\text { Stroke or systemic } \\
\text { embolism }\end{array}$ & $\begin{array}{l}\text { Stroke or } \\
\text { systemic } \\
\text { embolism }\end{array}$ & $\begin{array}{l}\text { Stroke or } \\
\text { systemic } \\
\text { embolism }\end{array}$ \\
\hline $\begin{array}{l}\text { Primary safety } \\
\text { endpoint }\end{array}$ & Major bleeding & $\begin{array}{l}\text { Major bleeding or } \\
\text { clinically relevant non- } \\
\text { major Bleeding }\end{array}$ & Major bleeding & Major bleeding \\
\hline VKA naïve & $50 \%$ & $38 \%$ & $43 \%$ & $41 \%$ \\
\hline $\begin{array}{l}\text { Mean TTR for INR } \\
\text { during study }\end{array}$ & 64 & 55 & 62 & 68 \\
\hline Inclusion criteria & & & & \\
\hline AF criteria & $\begin{array}{l}\text { AF at screening or } \\
\text { within } 6 \text { months }\end{array}$ & $\begin{array}{l}\text { AF recorded in } 30 \text { days } \\
\text { prior to randomization } \\
\text { and within } 1 \text { year }\end{array}$ & $\begin{array}{l}2 \text { episodes of } \mathrm{AF} \\
\text { or flutter } \\
\text { recorded } 2 \text { weeks } \\
\text { apart within } 1 \\
\text { year }\end{array}$ & $\begin{array}{l}\text { AF recorded } \\
\text { within } 1 \text { year }\end{array}$ \\
\hline LVEF & $40 \%$ or less & $35 \%$ or less & $40 \%$ or less & NA \\
\hline
\end{tabular}

\section{Exclusion criteria}

Valve disease

Stroke

Bleeding

$$
\begin{aligned}
& \text { Hemodynamically Hemodynamically Moderate-severe Moderate- } \\
& \text { prosthetic stenosis or } \\
& \text { mechanical }^{\S}
\end{aligned}
$$

Patient demographics

Age (yrs) 


\begin{tabular}{|c|c|c|c|c|}
\hline Characteristic & RE-LY & ROCKET & ARISTOTLE & ENGAGE \\
\hline Male gender (\%) & 63.2 & 60.3 & 64.5 & 61.9 \\
\hline \multicolumn{5}{|c|}{ Type of atrial fibrillation (\%) } \\
\hline Paroxysmal & 32.6 & 17.5 & 15.1 & 25.4 \\
\hline $\begin{array}{l}\text { Persistent/ } \\
\text { permanent }\end{array}$ & 67.4 & 82.5 & 84.9 & 74.6 \\
\hline \multicolumn{5}{|l|}{$\mathrm{CHADS}_{2}$ score $(\%)$} \\
\hline I & 32.2 & 0 & 34 & 0 \\
\hline II & 35.2 & 13 & 35.8 & 46.8 \\
\hline III-VI & 32.6 & 87 & 30.2 & 53.2 \\
\hline \multicolumn{5}{|l|}{ Comorbidities (\%) } \\
\hline Hypertension & 78.9 & 74 & 87.3 & 93.6 \\
\hline Previous TIA & 20.3 & 54.9 & 19.2 & 28.3 \\
\hline Diabetes & 23.1 & 40.4 & 25 & 36.2 \\
\hline Heart failure & 31.8 & 62.6 & 35.5 & 57.5 \\
\hline $\begin{array}{l}\text { Prior MI, CAD, } \\
\text { CABG }\end{array}$ & 28 & 17.3 & 14.5 & 33.3 \\
\hline \multicolumn{5}{|l|}{ Medications (\%) } \\
\hline ACE or ARB & 66.7 & 55.1 & 70.9 & 65.9 \\
\hline Beta-blockers & 63.7 & 65.1 & 63.6 & 66.3 \\
\hline Digoxin & 28.7 & 38.8 & 32 & 30 \\
\hline Amiodarone & 10.9 & NA & 11.1 & 11.8 \\
\hline Statins & 43.9 & 42.9 & 45 & 47.8 \\
\hline Gastric antacids & $17.9^{*}$ & NA & 18.5 & NA \\
\hline NSAIDS & 1.4 & NA & 8.2 & 1.1 \\
\hline Aspirin & 38.7 & 36.3 & 31.3 & 29.3 \\
\hline Thienopyridine & 5.5 & NA & 1.9 & 2.3 \\
\hline \multicolumn{5}{|c|}{ Creatinine clearance $(\%)$} \\
\hline$>80 \mathrm{ml} / \mathrm{min}$ & 32 & 32.2 & 41.2 & 37.2 \\
\hline$>50-80 \mathrm{ml} / \mathrm{min}$ & 47.4 & 46.7 & 41.9 & 43 \\
\hline$>30-50 \mathrm{ml} / \mathrm{min}$ & 19.7 & 21.1 & 15 & 18.4 \\
\hline$<30 \mathrm{ml} / \mathrm{min}$ & 0.005 & NA & 1.5 & 0.76 \\
\hline
\end{tabular}

* Total of proton pump inhibitors $13.9 \%$ and $\mathrm{H}_{2}$ antagonists $4 \%$.

$\S$ Bioprosthetic valves or valve repair patients were included.

Table 2. Study design and patient demographics. 


\subsection{INR control}

INR control is probably the most important factor in determining the non-inferiority of NOACs. All trials used the Rosendaal method of total time in therapeutic range (TTR, reflecting the percent of time the patient had an INR between 2 and 3) [20]. Overall, the TTR was 64\% in the RE-LY trial, 55\% in ROCKET, 62\% for ARISTOTLE, and 68\% for ENGAGE. These numbers clearly reflect that ROCKET had the least robust INR control in the warfarin arm leading to significant criticism of the trial.

Although these data were not analyzed further in the primary publications, the heterogeneity of INR management in the other trials appeared to impact clinical outcomes. In RE-LY, the INR control in east and South-East Asia was worse than centers in Europe and North America. The hazard ratio for major bleeding with dabigatran $150 \mathrm{mg}$ was $1.24(\mathrm{p}=0.03)$ when the TTR was $68 \%$ or more [11]. Additionally, higher rates of both thromboembolic events and major bleeds were seen with warfarin in centers with TTR $<57 \%$, even after adjusting for multiple other potential confounding variables [21]. The inadequacy of INR control in Asia may explain the more robust performance of dabigatran in those centers. Dabigatran $150 \mathrm{mg}$ also performed better than warfarin for a composite of stroke, systemic embolism, pulmonary embolism, myocardial infarction, and cardiovascular death with a hazard ratio of 0.64 for TTR $<57.1$ and hazard ratio of 1.19 for TTR $72.6(\mathrm{p}=0.006)$. This trend was mirrored in the mortality rate where dabigatran had an advantage at the centers with poor INR control (HR 0.67 vs $1.08, p=0.052$ ) [21].

Similar to dabigatran, edoxaban also had lower efficacy in patients with higher TTR. The hazard ratio for edoxaban $60 \mathrm{mg}$ vs warfarin in TTR $<57.7$ was 0.8 compared to hazard ratio of 1.07 for patients with TTR > 73.9. TTR [10]. A different issue was noted in ROCKET-AF, the TTR was low for the trial overall trial, and the resultant bleeding risks were equivalent between rivaroxaban and warfarin. However, the centers in the USA where TTR was around $64 \%$, patients taking rivaroxaban suffered 2.5-3.7 more bleeds per stroke prevented as compared to those taking warfarin [12]. Overall in patients with excellent INR control, warfarin may still be the drug of choice for stroke prevention in atrial fibrillation.

\subsection{Results and discussion}

The primary outcome in all four trials was stroke or systemic embolism, and the primary safety endpoint was major bleeding (RE-LY, ARISTOTLE, and ENGAGE), or combined major and clinically important non-major bleeding events (ROCKET). As illustrated in Table 3, patients randomized to the $150 \mathrm{mg}$ dose of dabigatran in RE-LY had a reduction in the primary outcome, experienced fewer ischemic as well as hemorrhagic strokes, and had a strong trend toward lower all-cause mortality in spite of experiencing higher rates of myocardial infarction [18]. This trend for higher myocardial infarction leads to several meta-analyses which showed approximately $30-40 \%$ increase in the rates of myocardial infarction with the use of dabigatran as compared to control arms including enoxaparin, placebo, and warfarin [22, 23]. However, in a post market analysis of 134,000 Medicare patients over 65 years of age done by the FDA did not show any difference between the incidence of myocardial infarction between Dabigatran (15.7 per 1000 person years) and warfarin (16.9 per 1000 person years, p 0.92) [24]. None 


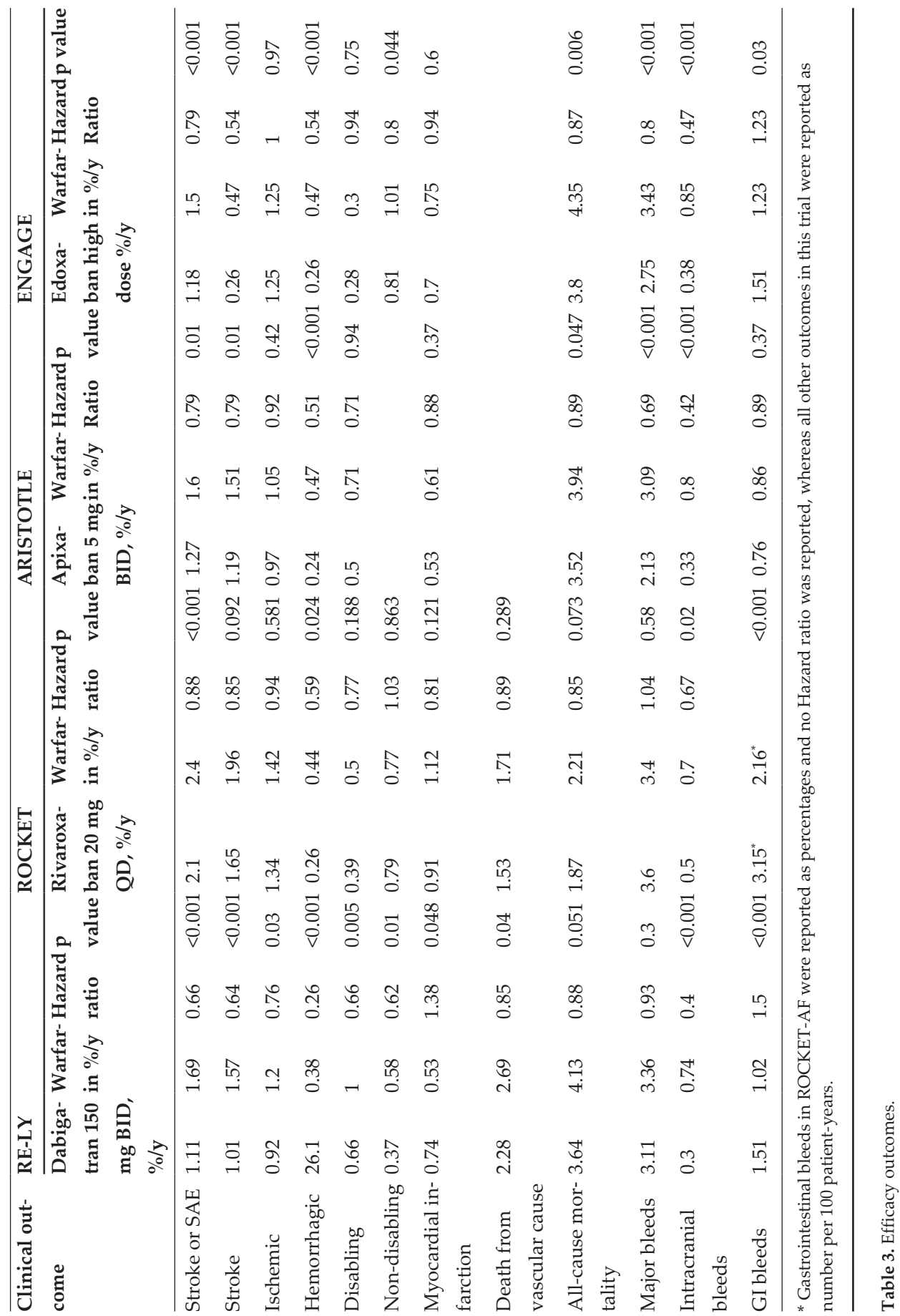


of the other NOAC had any signal towards myocardial infarction in their respective trials and the choice of using an alternative agent to dabigatran in the setting of known coronary artery disease should be individualized based on the clinical setting and physician discretion. There was no difference in overall major bleeding, where a significant reduction in intracranial hemorrhage was offset by a significantly higher rate of gastrointestinal bleeding.

For the intention-to-treat analyses in ROCKET-AF, rivaroxaban was noted to be non-inferior (but not superior) to warfarin in reducing the primary end point [19]. The reduction in ischemic stroke was not statistically significant as compared to the warfarin group and the outcomes were driven by a significant reduction in hemorrhagic stroke by rivaroxaban which may be reflective of the poor INR control in the trial. There was a trend toward reducing all-cause mortality in ROCKET, and like RE-LY, an equivalent bleeding endpoint was driven by a significant reduction of intracranial hemorrhage in the setting higher rates of gastrointestinal bleeds. In comparison, apixaban was the only drug to show statistically significant reduction in primary outcome compared to warfarin in both non-inferiority and superiority analyses. And, like the other trials, the reduction in the primary outcome was driven by a significant reduction of hemorrhagic strokes [17]. ENGAGE did show non-inferiority to warfarin in the reduction of primary outcomes, but in the prespecified superiority analysis, the difference was not statistically significant [14]. Unlike the prior studies of dabigatran and rivaroxaban, both ARISTOTLE and ENGAGE demonstrated a statistically significant reduction in all-cause mortality and major bleeding with the study drugs in comparison to warfarin [14, 17]. However, only apixaban showed no significant increase in gastrointestinal bleeding among all NOACs and it should be considered as the agent of choice in patients with prior (or at high risk for) gastrointestinal bleeding.

\section{Conclusion}

The approval of NOACs for stroke prevention in patients with NVAF has ushered a new era in this field with a multitude of options available for practitioners. Warfarin still may be the drug of choice in several clinical situations such as compliant patients with good INR control or those with valvular heart disease, etc. However, patient preference and the ease of use have made NOACs the preferred initial agent for stroke prevention in patients with NVAF. The subtle differences between the NOACs described throughout this chapter are aimed at providing an improved understanding of the intricacies with which these medications perform in the human body and thereby help guide decision-making.

\section{Conflicts of interest and source of funding}

No grant or other financial support was used for writing this chapter. Dr. Mehdirad has been a speaker for Apixaban. 


\section{Author details}

Keval K. Patel*, Ali A. Mehdirad and Richard Lee

*Address all correspondence to: kpatel74@slu.edu

Center for Comprehensive Cardiovascular Care, Saint Louis University School of Medicine, St Louis, MO, USA

\section{References}

[1] Fuster V, Ryden LE, Cannom DS, et al. ACC/AHA/ESC 2006 guidelines for the management of patients with atrial fibrillation. Circulation. 2006; 114:e257-e354.

[2] Hart RG, Benavente O, McBride R, Pearce LA. Antithrombotic therapy to prevent stroke in patients with atrial fibrillation: a meta-analysis. Ann Intern Med. 1999; 131:492-501.

[3] Agarwal S, Hachamovitch R, Menon V. Current trial-associated outcomes with warfarin in prevention of stroke in patients with non-valvular atrial fibrillation: a metaanalysis. Arch Intern Med. 2012; 172:623-631.

[4] You JJ, Singer DE, Howard PA, et al. Antithrombotic therapy for atrial fibrillation. Chest. 2012; 141(2_suppl):e531S-e575S.doi:10.1378/chest.11-2304.

[5] Coppens M, Eikelboom JW, Hart RG, Yusuf S, Lip GY, Dorian P, et al. The CHA2DS2VASc score identifies those patients with atrial fibrillation and a CHADS2 score of 1 who are unlikely to benefit from oral anticoagulant therapy. Eur Heart J. 2013; 34:170176

[6] Friberg L, Hammar N, Ringh M, Pettersson H, Rosenqvist M. Stroke prophylaxis in atrial fibrillation: who gets it and who does not? (SCAF-study). Eur Heart J. 2006; 27(16): 1954-1964.

[7] Gladstone D, Bui E, Fang J, Laupacis A, Lindsay MP, Tu JV, et al. Potentially preventable strokes in high-risk patients with atrial fibrillation who are not adequately anticoagulated. Stroke. 2009; 40:235-240.

[8] Dabigatran (Pradaxa Dabigatran tablets) prescribing information [package insert]. Ridgefield, CT: Boehringer Ingelheim Pharmaceuticals, Inc.; 2010.

[9] Rivaroxaban (Xarelto Rivaroxaban tablets) prescribing information [package insert]. Titusville, NJ: Janssen Pharmaceuticals Inc.; 2011.

[10] U.S. Food and Drug Administration. Daiichi Sankyo briefing document for the cardiovascular and renal drugs advisory committee on Edoxaban. Available at: http:// www.fda.gov/downloads/AdvisoryCommittees/CommitteesMeetingMaterials/ 
Drugs/CardiovascularandRenalDrugsAdvisoryCommittee/UCM420704.pdf. $\quad$ Accessed December 20, 2015.

[11] U.S. Food and Drug Administration. Boehringer Ingelheim advisory committee briefing document for Dabigatran. Available at: http://www.fda.gov/downloads/ advisorycommittees/committeemeetingmaterials/drugs/cardiovascularandrenaldrugsadvisorycommittee/ucm226009.pdf. Accessed December 20, 2015.

[12] U.S. Food and Drug Administration. Johnson \& Johnson briefing document for the cardiovascular and renal drugs advisory committee on Rivaroxaban. Available at: http://www.fda.gov/downloads/advisorycommittees/committeesmeetingmaterials/ drugs/cardiovascularandrenaldrugsadvisorycommittee/ucm270796.pdf. Accessed December 20, 2015.

[13] Apixaban (Eliquis Apixaban tablets) prescribing information [package insert]. Princeton, NJ: Bristol-Myers Squibb Co.; 2012.

[14] Giugliano RP, et al. (2013). Edoxaban versus warfarin in patients with atrial fibrillation. N Engl J Med. 369(22): 2093-2104.

[15] Büller HR, Décousus H, Grosso MA, Mercuri M, Middeldorp S, Prins MH, et al. Edoxaban versus warfarin for the treatment of symptomatic venous thromboembolism. N Engl J Med. 2013; 369:1406-1415.

[16] Edoxaban (Savaysa Edoxaban tablets) prescribing information [package insert]. Parsippany, NJ: Daiichi Sankyo, Inc.; 2011.

[17] Granger CB, Alexander JH, McMurray JJ, et al. Apixaban versus warfarin in patients with atrial fibrillation. N Engl J Med. 2011; 365:981-992.

[18] Connolly SJ, Ezekowitz MD, Yusuf S, et al. Dabigatran versus warfarin in patients with atrial fibrillation. N Engl J Med. 2009; 361:1139-1151.

[19] Patel MR, Mahaffey KW, Garg J, et al. Rivaroxaban versus warfarin in non-valvular atrial fibrillation. N Engl J Med. 2011; 365:883-891.

[20] Rosendaal FR, Cannegieter SC, van der Meer FJ, Briet E. A method to determine the optimal intensity of oral anticoagulant therapy. Thromb Haemost. 1993; 69:236-239.

[21] Wallentin L, Yusuf S, Ezekowitz MD, et al. Efficacy and safety of Dabigatran compared with warfarin at different levels of international normalized ratio control for stroke prevention in atrial fibrillation: an analysis of the RE-LY trial. Lancet. 2010; 376:975983.

[22] Uchino K, Hernandez AV. Dabigatran association with higher risk of acute coronary events: meta-analysis of non-inferiority randomized controlled trials. Arch Intern Med. 2012; 172(5):397-402

[23] Douxfils J, Buckinx F, Mullier F, et al. Dabigatran etexilate and risk of myocardial infarction, other cardiovascular events, major bleeding, and all-cause mortality: a 
systematic review and meta-analysis of randomized controlled trials. J Am Heart Assoc. 2014; 3(3):e000515

[24] FDA Drug Safety Communication: FDA Study of Medicare Patients Finds Risks Lower for Stroke and Death but Higher for Gastrointestinal Bleeding with Pradaxa (Dabigatran) Compared to Warfarin. FDA Drug Safety Communication: FDA Study of Medicare Patients Finds Risks Lower for Stroke and Death but Higher for Gastrointestinal Bleeding with Pradaxa (Dabigatran) Compared to Warfarin. US Food and Drug Administration, Nov. 11, 2012. Web. May 20, 2016. 
